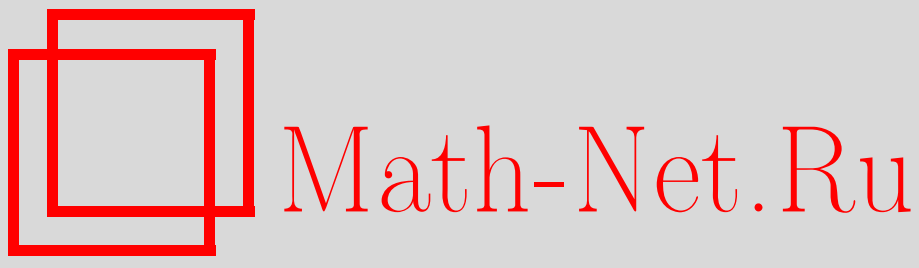

С. Л. Степанов, Экспериментальные исследования разрушения материалов при шейкообразовании и локализации пластических деформаций по жесткопластической схеме Оната и Прагера, Вестн. Сам. гос. техн. ун-та. Сер. Физ.-мат. науки, 2004, выпуск 26, 127-130

DOI: https://doi.org/10.14498/vsgtu189

Использование Общероссийского математического портала Math-Net.Ru подразумевает, что вы прочитали и согласны с пользовательским соглашением http://www . mathnet.ru/rus/agreement

Параметры загрузки:

IP: 34.227 .88 .159

26 апреля 2023 г., 14:56:02

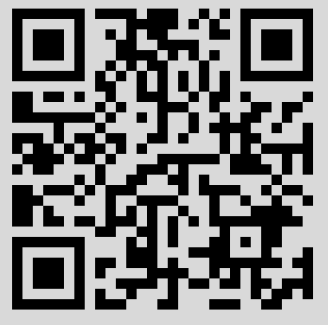




\section{ЭКСПЕРИМЕНТАЛЬНЫЕ ИССЛЕДОВАНИЯ РАЗРУШЕНИЯ МАТЕРИАЛОВ ПРИ ШЕЙКООБРАЗОВАНИИ И ЛОКАЛИЗАЦИИ ПЛАСТИЧЕСКИХ ДЕФОРМАЦИЙ ПО ЖЕСТКОПЛАСТИЧЕСКОЙ СХЕМЕ ОНАТА И ПРАГЕРА}

Предложены схема и методика экспериментальных исследований ниспадающего участка диаграммь деформирования при локализации пластических деформащий по жесткопластической схеме Оната и Прагера на разрывной машине с мягкой системой нагружения. Получил экспериментальное подтверждение линейный характер закритической стадии деформирования для стали Ст3, соответствуюший этой жесткопластической схеме. Рассмотрена возможность использования при упругопластическом разрушении материалов таких деформационных критериев, как предельная деформация и предельное сужение. Показана их эквивалентность.

В механике упругопластического разрушения значительный интерес представляет определение предельного состояния образцов и элементов конструкций с трещиноподобными дефектами, у которых образуются соизмеримые с их размерами пластические зоны, не приводящие, однако, к общему течению ослабленного сечения. В таких случаях основным является вопрос о напряженно - деформированном состоянии материала в пластических областях. В настоящее время согласно достаточно распространенному и, в известной степени, обоснованному мнению [1-3] пластические зоны трактуются как области шейкообразования, в которых происходит локальная потеря устойчивости процесса деформирования материала, в то время, как весь образец деформируется устойчиво до начала общего разрушения. Такой подход, в свою очередь, требует исследования процесса шейкообразования вплоть до исчерпания материалом образца способности устойчиво деформироваться и построения соответствующих модельных представлений.

В [4] пластические области у вершин трещины рассматривались как зоны шейкообразования при локализации пластических деформаций по жесткопластической схеме, предложенной Онатом и Прагером [5], которая определяет линейную связь между напряженными на берегах жесткой зоны и соответствующими смещениями. Эта зависимость, согласно [6], имеет вид:

$$
\sigma_{y}=\sqrt{2} \sigma_{s}\left(1-\frac{2 u}{h}\right),
$$

где $\sigma_{y}$ - растягивающие напряжения, $u$ - смещения берегов жесткой зоны, $\sigma_{s}$ - предел текучести материала на растяжение, $h$ толщина пластины.

Полученную зависимость можно рассматривать как ниспадающую ветвь диаграммы деформирования материала при шейкообразовании, имеющую линейный характер, и интерпретировать ее как характеристику локальной неустойчивости процесса деформирования в пластических областях при устойчивом деформировании всего тела в целом.

Для экспериментальных исследований предложенного модельного представления была выбрана пластическая сталь Ст3 с выраженной площадкой текучести на диаграмме деформирования. Образцы изготавливались из плиты толщиной 10 мм, которая фрезеровалась до толщины $8 \pm 0,05$ мм. Ширина образцов выдерживалась равной 20 мм. В каждом образце с двух сторон фрезерованием формировались канавки перпендикулярно продольной оси и создавались рабочая часть образца номинальным сечением $2 \times 2$ мм (рис. 1 ). Поскольку толщина образца значи-

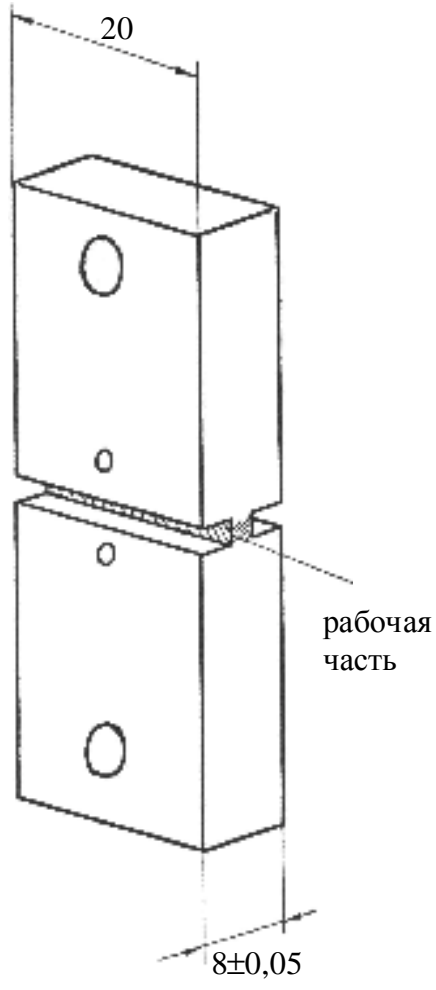

Р и с. 1. Схема образца тельно больше размеров рабочей части, процесс деформирования последней близок к жесткопластическому течению по схеме Оната и Прагера. В каждом образце изготавливались четыре отверстия: два для крепления образца в захватах разрывной машины и два меньшего диаметра для крепления датчика перемещений краев рабочей части. После механической обработки все образцы подвергались отпуску для снятия поверхностного наклепа. 
Для образцов таких размеров из Ст3 разрушающая нагрузка при $\sigma_{b} ; 400$ МПа составляет величину порядка 20 тонн. Поскольку разрывных машин с жесткой системой нагружения и такими максимальными усилиями в распоряжении автора не было, испытания проводились на разрывной машине $\mathrm{P}-50$ с мягкой системой нагружения. Это потребовало изменить схему эксперимента и разработать соответствующую методику проведения испытаний, позволяющую осуществлять контроль по перемещениям и поддерживать устойчивое деформирование образцов при локализации деформаций по жесткопластической схеме согласно (1) вплоть до исчерпания материалом в рабочей части образцов способности деформироваться. Для этого в схему эксперимента был добавлен упругий элемент, представляющий собой составную балку, лежащую на двух опорах и набранную из закаленных пластин 30ХГСНА толщиной от 1 до 5 мм. Это позволило регулировать жесткость упругого элемента как с помощью изменения расстояния между опорами, так и подбором количества пластинок.

Схема эксперимента приведена на рис.2. Здесь 1- фундамент разрывной машины, 2 - нижний захват, 3 - образец, 4 - датчик перемещений краев рабочей части образца, 5 - верхний захват, 6 - опоры упругого элемента, 7 - упругий элемент (составная балка), 8 - средняя опора, 9 - верхний силовой пояс разрывной машины, 10 - рабочий цилиндр, 11 - верхняя силовая балка разрывной машины, 12 - датчик прогибов упругого элемента. Стрелкой показано направление растяжения.

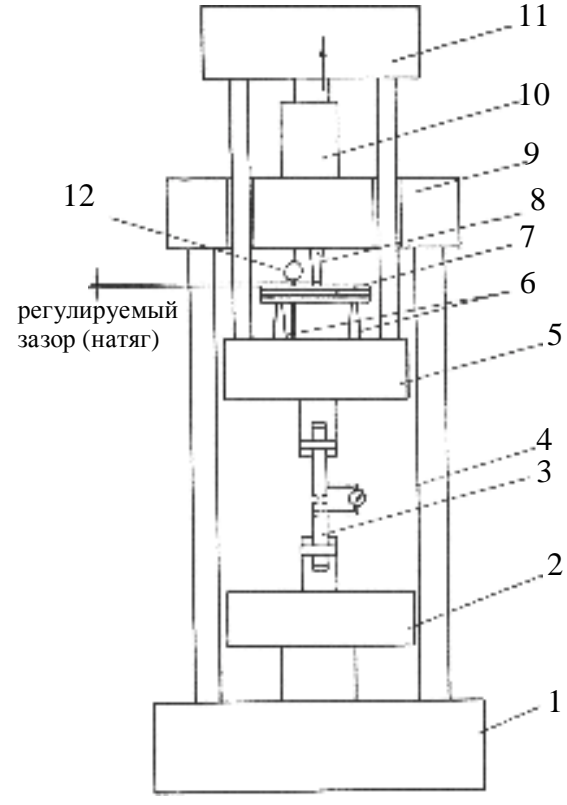

Р и с. 2. Схема эксперимента

Испытания проводились в следующем порядке. Вначале снималась диаграмма зависимости усилия от перемещений (P - $u$ ) для упругого элемента без образца. Она приведена на рис. 3. Видно, что эта зависимость имеет нелинейный участок до перемещения, равного 0,6 мм. Далее начинается близкий к линейному участок, на котором отмечены точки, соответствующие определенным значениям прогиба упругой балки, снимаемые с датчика 12. Поэтому при проведении испытаний образцов с помощью регулируемой средней опоры 8 осуществлялся предварительный натяг упругого элемента на эту величину, после чего датчики 4 и 12 выставлялись на ноль.

При испытании образцы с помощью регулятора разрывной машины нагружались усилиями, соответствующими следующим значениям расхождения берегов рабочей части, определяемым по датчику 4: 0,1 мм, 0,2 мм и далее с шагом 0,1 мм. Этим же датчиком фиксировалось предельное значение этого расхождения в момент разрушения. Одновременно с датчика 12 снимались величины прогиба упругого элемента, соответствующие этому ряду значений расхождения рабочей части образца.

Далее для получения диаграммы усилие - смещение для рабочей части образца на графике суммарной диаграммы, полученной на записывающем устройстве разрывной машины, строилась скорректированная (учитывающая предварительный натяг) тарированная (см. рис. 3) диаграмма упругого элемента, и графически вычиталась из суммарной диаграммы $\mathrm{P}-u$. На рис. 4 в качестве примера показаны суммарная (кривая 1) и результирующая (кривая 2) диаграммы. Эти кривые построены в координатах усилие - перемещения краев рабочей части. Момент разрушения образца показан звездочкой. Видно, что спадающая ветвь для материала Ст3 при локализации пластических деформаций по схеме Оната и Прагера имеет характер, близкий к линейному.

После разрушения образцов с помощью регулятора разрывной машины производилось плавное снижение нагрузки, при этом кривая разгрузки после переходного периода выходила на диаграмму упругого элемента (кривая 3 на рис.4). Это доказывает, что диссипацией энергии в упругом элементе из-за наличия трения между упругими пластинками можно пренебречь. Таким образом, жесткопластическое решение Оната и Прагера при шейкообразовании получило экспериментальное подтверждение.

По предложенной методике было испытано восемь образцов. Основные результаты проведенных экспериментов представлены в таблице. 
Здесь $P_{\text {разр }}$ - усилие на границе жесткой зоны и рабочей части в момент разрушения образца, определяемое на кривой 2 (рис. 4); $u_{n p}$ - соответствующее расхождение берегов жесткой зоны; $\varepsilon_{n p}=u_{n p} / h$ - предельная деформация рабочей части; $h=2,15$ мм - начальная высота рабочей части; $\psi_{n p}$ - сужение рабочей части в момент разрушения, замеряемое на разрушенных образцах с помощью микроскопа.

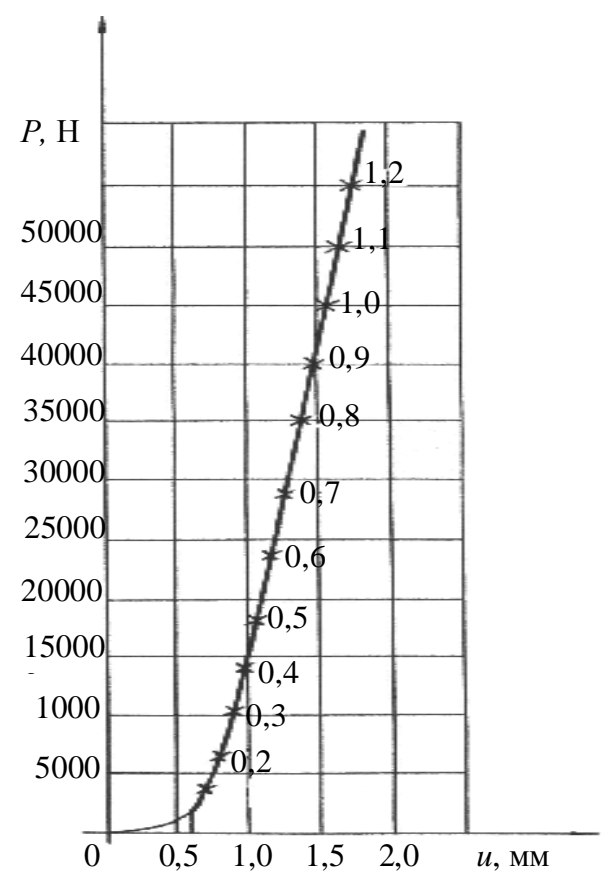

Р и с. 3. Тарированная диаграмма $P-u$ для упругого элемента

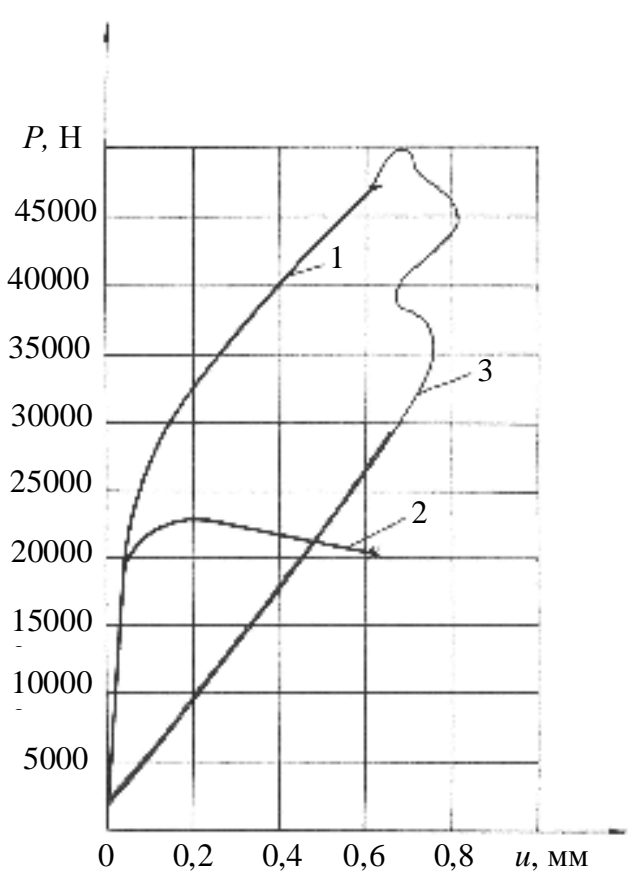

Р и с. 4. Диаграмма $P$-и рабочей части образца

Результаты эксперимента

\begin{tabular}{|c|c|c|c|c|c|c|}
\hline $\begin{array}{c}\text { Образец } \\
\text { № }\end{array}$ & $\begin{array}{c}\text { Сечение } \\
\text { мм×мм }\end{array}$ & $\begin{array}{c}\text { Разрушающая } \\
\text { нагрузка } \\
P_{\text {разр }}, \mathrm{H}\end{array}$ & $\begin{array}{c}\text { Предельное } \\
\text { расхождение } \\
u_{n p}, \text { мм }\end{array}$ & $\begin{array}{c}\text { Предельная } \\
\text { деформация } \\
\varepsilon_{n p}\end{array}$ & $\begin{array}{c}\text { Временное } \\
\text { сопротивление } \\
\text { отрыву, МПа }\end{array}$ & $\begin{array}{c}\text { Предельное } \\
\text { сужение } \\
\Psi_{n p}\end{array}$ \\
\hline 1 & $2,15 \times 2,15$ & 23600 & 0,7 & 0,326 & 435 & 0,32 \\
\hline 2 & $2,2 \times 2,15$ & 23800 & 0,63 & 0,298 & 437 & 0,3 \\
\hline 3 & $2,1 \times 2,15$ & 22700 & 0,65 & 0,31 & 420 & 0,31 \\
\hline 4 & $2,15 \times 2,15$ & 20750 & 0,71 & 0,33 & 384 & 0,32 \\
\hline 5 & $2,1 \times 2,15$ & 21600 & 0,69 & 0,33 & 405 & 0,33 \\
\hline 6 & $2,1 \times 2,15$ & 21800 & 0,62 & 0,295 & 409 & 0,3 \\
\hline 7 & $2,25 \times 2,15$ & 23800 & 0,7 & 0,311 & 432 & 0,31 \\
\hline 8 & $2,15 \times 2,15$ & 22600 & 0,61 & 0,288 & 418 & 0,29 \\
\hline
\end{tabular}

Образцы разрушались, как правило, в середине рабочей части. Разрушение происходило отрывом без образования заметных губ среза на базовых поверхностях рабочей части, что косвенно подтверждает факт локализации деформаций по схеме Оната и Прагера. Об этом же убедительным образом говорит и практическое совпадение экспериментальных значений предельной деформации $\varepsilon_{n p}$ и предельного сужения $\psi_{n p}$.

Анализ полученных экспериментальных результатов позволяет сделать следующие выводы: 
1) разработаны и реализованы схема и методика испытаний, позволяющие на разрывной машине с мягкой системой нагружения исследовать ниспадающую ветвь диаграммы деформирования;

2) получила экспериментальное подтверждение возможность локализации деформаций при шейкообразовании по жесткопластической схеме Оната и Прагера;

3) показано, что для определения предельного состояния упругопластических тел с трещинами, у вершин которых образуются развитые пластические зоны, можно использовать такие деформационные критерии, как предельная деформация $\varepsilon_{n p}$ и предельное сужение $\psi_{n p}$ при шейкообразовании, а также экспериментально доказана их эквивалентность.

\section{БИБЛИОГРАФИЧЕСКИЙ СПИСОК}

1. Волков С.Д. Проблема прочности и механика разрушения // Проблемы прочности. 1978. №7. С. 3 - 12.

2. Никитин Л.В., Рыжак Е.И. Об осуществимости состояний материала, соответствующих «падающему» участку диаграммы // Изв. АН СССР. МТТ. 1986. №2. С. 155 - 161.

3. Лебедев А.А., Чаусов Н.Г., Марусий О.И. и др. Кинематика разрушения листовой аустенитной стали на заключительной стадии деформирования // Проблемы прочности. 1989. №3. С. 16 - 21.

4. Быковщев Г. И. Лукашев Л.Г., Степанов С.Л. Об одной модели разрушения в идеальных упругопластических средах // Проблемы прочности. 1982. №3. С. 72 - 75.

5. Онат E., Прагер В. Образование шейки при пластическом течении растягиваемого плоского образца // Механика. Сб. трудов. М.: Изд-во АН СССР. 1955. №4 (32). С. 93 - 97.

6. Хромов А.И. Деформация и разрушение жесткопластических тел // Владивосток: Дальнаука, 1996. 180 с.

Поступила 27.11.2003 2. 